\title{
The mARM spatially distributed soil evolution model: A computationally efficient modeling framework and analysis of hillslope soil surface organization
}

\author{
Sagy Cohen, ${ }^{1,2}$ Garry Willgoose, ${ }^{1}$ and Greg Hancock ${ }^{2}$ \\ Received 10 December 2008; revised 17 March 2009; accepted 25 March 2009; published 15 July 2009.
}

[1] Hillslope surface armouring and weathering processes have received little attention in geomorphologic and hydrologic models due to their complexity and the uncertainty associated with them. Their importance, however, in a wide range of spatial processes is well recognized. A physically based armouring and weathering computer model

(ARMOUR) has previously been used to successfully simulate the effect of these processes on erosion and soil grading at a hillslope scale. This model is, however, computationally complex and cannot realistically be applied over large areas or over long periods of time. A simplified process conceptualization approach is presented (named mARM) which uses a novel approach of modeling physical processes using transition matrices, which is orders of magnitude faster. We describe in detail the modeling framework. We calibrate and evaluate the model against ARMOUR simulations and show it matches ARMOUR for a range of conditions. The computational efficiency of mARM allowed us to easily examine time- and space-varying relationships between erosion and physical weathering rates at the hillslope scale. For erosion-dominated slopes the surface coarsens over time, while for weathering domination the surface fines over time. When erosion and weathering are comparable in scale a slope can be weatheringdominated upslope (where runoff and therefore erosion is low) and armouring-dominated downslope. In all cases, for a constant gradient slope the surface armour coarsens downslope as a result of a balance between erosion and weathering. Thus even for weathering-dominated slopes the surface grading catena is dependent on armouring through the balance between weathering and armouring. We also observed that for many slopes the surface initially armours but, after some period of time (space- and ratedependent), weathering begins to dominate and the surface subsequently fines. Depending on the relative magnitude of armouring and weathering the final equilibrium grading of the slope may be finer or coarser than the initial conditions. The results demonstrate the complexity of the evolution of surface grading and the balance between the armouring and weathering processes. They also point toward inherent organization of surface grading on the hillslope driven by erosion even for extremely high weathering rates. The implications for natural landforms are discussed. We also plot and quantify, for the first time, a log-log relationship between surface grading, contributing area and slope for a range of weathering rates. The results show that this log-log relationship is robust, the $\log -\log$ scaling is constant in space, and true even for extreme weathering rates. This has potentially important implications for soil geomorphology. It suggests that an analytical solution can be found for soil grading catena. This might allow us to more easily map soil distribution as a function of topographic characteristics.

Citation: Cohen, S., G. Willgoose, and G. Hancock (2009), The mARM spatially distributed soil evolution model: A computationally efficient modeling framework and analysis of hillslope soil surface organization, J. Geophys. Res., 114, F03001,

doi:10.1029/2008JF001214.

\footnotetext{
${ }^{1}$ School of Engineering, University of Newcastle, Callaghan, New South Wales, Australia.

${ }^{2}$ School of Environmental and Life Sciences, University of Newcastle, Callaghan, New South Wales, Australia.
}

Copyright 2009 by the American Geophysical Union. 0148-0227/09/2008JF001214\$09.00

\section{Introduction}

[2] Armouring is the process of surface coarsening caused by removal of fine material from the top layer. Soil armouring occurs when a mixture of fine and coarse particles are exposed to overland flow which, over time, preferentially erodes the fine particles. When all transport- 
able material has been removed a stable armour layer is formed. Consequently if the overland flow does not subsequently increase, the sediment transport, and thus erosion, is reduced to zero. If the overland flow is higher than the armour-forming flow the armoured layer may be either further coarsened, or destroyed [Willgoose and Sharmeen, 2006].

[3] In contrast weathering is the breakdown and/or alteration of rock and material near the earth surface. The overall weathering process can be divided to two interrelated processes: physical and chemical weathering. Physical weathering is the breakdown of rock to smaller fragments by mechanical processes such as abrasion by water, mineral and ice creation, expansion and contraction due to temperature fluctuations and biological activity. In chemical weathering rock is usually dissolved, oxidized or reduced by a variety of chemical reactions [Birkeland, 1974]. The overall weathering process is an interaction between physical and chemical weathering as physical weathering may depend on chemical weakening of the rock and chemical weathering acts on available fresh mineral surface exposed by physical breakdown [Riebe et al., 2004]. Physical weathering is believed to dominate the breakdown of large soil particles at the surface [Yokoyama and Matsukura, 2006]. This process influences the fine sediment availability and soil grading which increase sediment transport [Sharmeen and Willgoose, 2006]. This interaction creates the coupling between erosion (armouring) and weathering. In this paper we focus on physical, rather than chemical, weathering of the particles on the soil surface. Therefore, unless otherwise mentioned, we use the term "weathering" to describe the process of physical breakdown of rock or soil particles.

[4] The net effect of armouring on hillslope erosion and weathering has generally been neglected in soil erosion and landform evolution models despite the growing recognition of its importance in erosion processes [Willgoose and Sharmeen, 2006]. Most armour models are for river channel beds. In those models the armour layer composition is predicted either in a single step method or a time varying simulation. For the single step models the prediction of the final armour grading is based on probability [e.g., Gessler, 1970] or empirically derived equations [e.g., Little and Mayer, 1976; Nouh, 1990; Parker and Sutherland, 1990]. In the time varying simulations armour evolution is calculated by the selective entrainment of the finer bed sediments [e.g., Ashida and Michiue, 1971; Proffitt, 1980; Hoey and Ferguson, 1994]. Willgoose and Sharmeen [2006] simulated the effect of time-varying surface armouring on sediment flux and erosion on hillslopes using a physically based model (i.e., ARMOUR). ARMOUR, a one-dimensional hillslope soil erosion model was used to simulate long-term erosion and armour development in two contrasting mine spoils; one cohesive, the other noncohesive.

[5] Armour evolution is also controlled by weathering. Rock weathering literature is broad and deals mostly with rock fragmentation mechanisms and size distribution for applications different from that proposed here [Lerman, 1979; Klimpel and Austin, 1965; Robertson et al., 1997; Green et al., 2006; Wells et al., 2006]. There is little emphasis on weathering of surface material or long-term simulations of its influence on erosion and landform evolution. Sharmeen and Willgoose [2006] integrated a variety of physical weathering mechanisms into their ARMOUR model. They used it to investigate the interaction between weathering and armouring and the net effect on erosion and surface soil grading. They found that the weathering rate has a profound influence on the armour layer, sediment flux, and erosion. A high weathering rate can prevent the creation of an armour layer resulting in a "transport-limited" regime in which the bed consists of an excess of fine transportable material where sediment collects on the surface and runoff has insufficient transport capacity to remove it. On the other hand a low weathering rate may result in "weatheringlimited" regime in which the armour layer is fully developed (i.e., it is too coarse to be eroded) and the runoff can only remove the fine material generated by weathering. Sharmeen and Willgoose [2006] identified an interaction between the two regimes (called "weathering/transport limited") where there was a balance between coarsening from armouring and fining from weathering. The balance led to an equilibrium surface sediment grading that is different from the grading of the underlying material.

[6] Sharmeen and Willgoose [2006] used ARMOUR to simulate the long-term one-dimensional hillslopes of mine spoils. Among other things, their work has demonstrated the attractiveness of the ARMOUR model and the potential of its physically based conceptualization of soil evolution to study landforms and soils. Their one-dimensional simulations were an important initial stage for modeling more complex two-dimensional problems such as catchments and provided valuable insights into the organization of hillslope soil grading in response to erosion and weathering processes. However, they are a simplified view of the hillslope. In order to simulate the armouring and weathering processes in natural systems at larger scale than the hillslope and integrate them into erosion and landform evolution models two dimensional simulations are needed.

[7] The main limiting factor in ARMOUR is the numeric complexity of its physics and the consequent high computational requirements and long runtimes. This numerical issue prevents its implementation for larger than hillslope scale. Here we will show that simplifying ARMOUR is possible. The physically based model will be reformulated as a state-space matrix model. This will dramatically reduce runtimes. This reformulation is the focus of this paper.

[8] This paper presents (1) a description of the physically based ARMOUR model, (2) a detail description of our model (mARM), (3) the calibration procedure of mARM using the ARMOUR model and laboratory experimental data, (4) a parametric study using mARM exploring the implications of the armouring and weathering physics, (5) a comparison of armouring-weathering simulations under varying weathering rates, and (6) calculation of a relationship between the armour $d_{50}$ and geomorphology statistics for a range of weathering rates.

\section{ARMOUR Model}

[9] ARMOUR is a physically based one-dimensional model simulating temporal and spatial varying soil erosion and armour development [Willgoose and Sharmeen, 2006]. It uses commonly accepted sediment flux and erosion equations to simulate the amount of sediment entrained or 
deposited in each node down the hillslope at each time step. ARMOUR simulates sediment flux and soil grading based on interaction between three layers: (1) water layer in which the sediment transport occurs and covers the entire width of the hillslope; (2) armour layer which is the upper thin soil layer where transportable particles are entrained or deposited; (3) subsurface layer which is a semi-infinite depth soil reservoir mantle used as storage for deposited material or source of eroded material.

[10] In ARMOUR the sediment flux is estimated for a given flow discharge as a function of bed shear stress, median diameter of the material in the water, slope, bed resistance and soil characteristics. For each node and within each layer continuity of sediment is applied with the sediment in each grading size range being transferred between each layer and between each node by modeled physics. At a node the balance between the incoming sediment from upstream and the sediment leaving that node is used to calculate the amount of erosion or deposition. An entrainment function is used to determine how that net amount of erosion or deposition is distributed across the grading size ranges. Over the long-term this selective entrainment in different grading size ranges changes the surface soil grading. The size selection in the entrainment function has two key components. The first component is the Shields entrainment function threshold which is used to determine the maximum particle size that can be entrained for given flow conditions. The second component is the distribution of entrainment across the grading ranges that are finer than the Shields function threshold. Seven entrainment modes are available in ARMOUR. Willgoose and Sharmeen [2006] found that the hiding entrainment mechanism of Andrews and Parker [1987] produced the best match to field data. In this mechanism smaller particles are hidden from the flow by the courser particles that protrude from the bed. This reduces the entrainability of the finest fraction. The selective entrainment is thus a function of the armour layer grading and the proportion of coarser material. A second entrainment mechanism, called "material availability," was also found to be well correlated to field data. In this mechanism particles are entrained as a function of their relative availability on the surface. In this paper we use the material availability entrainment mechanism because its conceptual framework can be more directly and simply expressed by the matrices approach used in mARM. We do this to simplify the discussion that follows, rather than as a result of any inherent limitation of the approach.

[11] The weathering module in ARMOUR simulates the breakdown of the armour layer particles over time. It has two components: (1) the rate of breakdown of individual particles, parameterized as a probability that an individual particle will fracture in any time step, and (2) the grading characteristics of the daughter particles generated when breakdown occurs. Both processes may be space, time and particle size dependent. The depth of the weathered mantle is constant in space and time and is assumed equal to the depth of the armour layer. Weathering thus only occurs in the armour layer and not in the underlying source material.

[12] While the weathering physics are defined with respect to an individual particle the aggregate effect of weathering occurs in ARMOUR by modifying the grading of the layers within its domain. In every iteration the volume and number of particles in each grading group in the weathering mantle is calculated. Those particles are then weathered according to the breaking mechanism chosen by the user. The new number of particles in each size group is then used to recalculate the size distribution of the weathering domain. Conservation of mass occurs in the weathering process (i.e., there is no mass loss as might occur with chemical weathering) and parent and daughter particles are assumed to be spherical.

[13] ARMOUR can simulate two types of weathering breakage mechanism: (1) granular disintegration (akin to spalling but creating rounded daughter products rather than rock flakes) of a particle around its periphery resulting in the reduction of the particle volume and creation of a number of daughter particles, with the diameter of the daughter particles being equal to the depth of the layer that disintegrated from the parent particle; and (2) body fracture in which the parent particle splits into a number of daughter particles. Wells et al. [2008] compared these models to laboratory salt weathering experiments and found a best fit with a mechanism that split the parent particle into two daughter fragments. The best fit was when the two daughter fragments had equal volume. We therefore used the mechanism where particles split in two equal volume daughter fragments.

\section{Modeling Approach}

\subsection{Matrix Approach}

[14] Our approach involves simulating the evolution of soil grading through time. The soil grading at any given time is represented by a vector called the state vector $g$ (in the state-space literature). In this paper the entries in the state vector, $g_{i}$, are either the mass or proportion of sediment in the grading size range $i$. The transition from the state at any given time to the state at the next time step is described by a matrix equation. It describes both how any given state changes with time and how each of the states at one time, $t_{1}$, are related to the states at the next time step $t_{2}$.

$$
\underline{g}_{t_{2}}=\mathbf{R} \underline{g}_{t_{1}}
$$

where the matrix $\mathbf{R}$ is called the transition matrix and is typically a function of the size of the time step $\left(t_{2}-t_{1}\right)$ [Ross, 1993]. Note that any set of coupled differential equations (e.g., the physics in ARMOUR) can also be expressed with equation (1). The advantage here is that we can explicitly formulate the stochastic breaking process used in the weathering model in the same form. The details of this formulation follow below.

[15] In mARM the state is the percentage of material in a soil grading class so that the state vector is the grading distribution of the surface soil. The transition matrix parameterises the change of that grading by the weathering and armouring processes so that equation (1) evolves the soil grading of the simulated landscape.

\subsection{The mARM Model Outline}

[16] The mARM simulates each physical process as a multiplicative change to the state. If we have a single process, we will call it $a$, with a corresponding transition 
matrix $\mathbf{R}$ then the evolution of the grading vector over one time step is

$$
\left.\underline{g}_{t+1}=\mathbf{R}\right] \underline{g}_{t}
$$

which is equation (1) where one time step is $\left(t_{2}-t_{1}\right)$ that can be extracted to multiple processes by assuming that the effect of one process occurs on the result of the other processes. For instance, if we have three physical processes that can be considered independent at the timescale of the single time step, called $a, b, c$, with corresponding transition matrix in equation (1) of $\mathbf{R}, \mathbf{S}$, and $\mathbf{T}$ then the combined effect of these processes on the soil grading is

$$
\underline{g}_{t+1}=\mathbf{T S R} \underline{g}_{t}
$$

where the order of the matrix multiplication implies that process $a$ acts on the grading first, $b$ operates second on the result of process $a$, and $c$ is third and operates on the results of process $b$. This disaggregation of processes is often called "operator splitting" [Celia and Gray, 1991]. In the following sections we describe the physics we have used for each of the modeled processes.

[17] Equations (1) and (3) follow the traditional presentation of transition matrices. In the discussion that follows it is more convenient to work with the marginal transition matrix than the actual transition matrix. In this case

$$
\mathbf{R}=\mathbf{I}+\mathbf{M}
$$

where $\mathbf{I}$ is the identity matrix (the identity matrix is 1 for the diagonal elements and 0 elsewhere, so that $\underline{g}=I \underline{g}$ ) and $\mathbf{M}$ is the marginal transition matrix. The change in grading over a time step is proportional to matrix $\mathbf{M}$. The advantage of formulating the matrices in this form is that the rates of the process represented by $\mathbf{M}$ (e.g., the weathering rate) can be changed simply by multiplying the marginal matrix by a scaling factor. For example, doubling the process rate is achieved by the multiplying the marginal transition matrix by 2 so that

$$
\begin{aligned}
& \mathbf{A}(1 \times)=\mathbf{I}+\mathbf{M} \\
& \mathbf{A}(2 \times)=\mathbf{I}+2 \mathbf{M}
\end{aligned}
$$

[18] In the discussion below we are referring to the marginal transition matrix unless otherwise noted. In marginal transition matrix form equation (3) is

$$
\underline{g}_{t+1}=(\mathbf{I}+\mathbf{C})(\mathbf{I}+\mathbf{B})(\mathbf{I}+\mathbf{A}) \underline{g}_{t}
$$

where $\mathbf{A}, \mathbf{B}$, and $\mathbf{C}$ are the marginal transition matrices corresponding to the transition matrices $\mathbf{R}, \mathbf{S}$, and $\mathbf{T}$. Both the marginal and transition matrices are nondimensional by definition but $\mathbf{A}, \mathbf{B}$, and $\mathbf{C}$ are still potentially dependent on the size of the time step.

\subsubsection{Erosion and Armouring}

[19] As in ARMOUR we consider a thin surface layer (the armour) in which the grading changes with time, with a semi-infinite subsurface of material below the armour layer with a grading that does not change through time. The lack of change with time of the underlying material is not required by the following derivations, but is an assumption we make in the remainder of this paper to simplify the presentation. At each step material is eroded from the armour layer and to maintain mass continuity in the armour layer the armour layer is recharged using material from the subsurface. To ensure mass continuity it is convenient to work in terms of the total mass of sediment in each grading size range, $i$, per unit area of soil surface, $G_{i}$, rather than the proportion of sediment by mass in the grading range, $g_{i}$. In the armour layer the two are related by the equation

$$
G_{i}=\rho_{b} D g_{i}
$$

where $D$ is the depth of the armour layer and $\rho_{b}$ is the bulk density of the sediment. For simplicity we assume that the bulk density of the sediment does not change with changes in the grading distribution. The erosion step of the calculations is then

$$
\underline{G}_{e}=\underline{G}_{0}-\frac{\Delta E}{D} \mathbf{A} \underline{G}_{0}=\left[\mathbf{I}-\frac{\Delta E}{D} \mathbf{A}\right] \underline{G}_{0}
$$

where $\underline{G}_{0}$ and $G_{e}$ are the total mass grading vectors for before and after the erosion step of the calculation, respectively, $\Delta E$ is the depth of erosion during the time step, $D$ is the armour depth, and $\mathbf{A}$ is the marginal transition matrix for the erosion process. The sign convention in equation (8) means that $\mathbf{A}$ is defined positive for deposition. The transition matrix determines what the distribution of entrainment from each of the grading size ranges is while $\frac{\Delta E}{D}$ determines the absolute amount of erosion (normalized by the depth of armour layer). The normalization of the transition matrix A by $\left(-\frac{\Delta E}{D}\right)$ is done to remove the time step size dependence in equation (6). Implicit in our assumption that $\mathbf{A}$ does not vary during the time step is an assumption that $\frac{\Delta E}{D}$ is small so that erosion physics do not change during the time step. This assumption is twofold. First as $\frac{\Delta E}{D}$ increases the accuracy of this step decreases, because we have explicitly disaggregated this process from the other processes below. Second as the grading changes the transition matrix A will change as a result of the armouring process itself, though the processes of hiding and selective entrainment of the different grading size ranges [Parker and Klingeman, 1982].

[20] After applying equation (8) the total mass of sediment per unit area in the armour layer, $\sum G_{e i}$, will be less than before erosion by $\Delta E$. Since we require that the depth of the armour layer is constant with time we must recharge the armour layer with sediment from the semi-infinite layer underlying the armour. The recharge step is

$$
\underline{G}_{r}=\underline{G}_{e}+\Delta E \rho_{b} \underline{g}_{s s}=\underline{G}_{e}+\frac{\Delta E}{D} \underline{G}_{s s}
$$

where $\underline{G}_{r}$ is the total mass grading vector for the armour after recharge with subsurface material, and $g_{s s}$ and $\underline{G}_{s s}$ are the grading and total mass vectors for the subsurface underlying material per unit area, respectively. We can then combine equations (8) and (9) to yield the equation for the 
erosion of the armour layer (which is mass conservative for the armour layer) to yield

$$
\underline{G}_{r}=\underline{G}_{0}-\frac{\Delta E}{D} \mathbf{A} \underline{G}_{0}+\frac{\Delta E}{D} \underline{G}_{s s}
$$

and if we reformulate this in terms of the grading vector, $g$, using equation (7) and dividing through by $\rho_{b} D$

$$
\underline{g}_{r}=\left[\mathbf{I}-\frac{\Delta E}{D} \mathbf{A}\right] \underline{g}_{0}+\frac{\Delta E}{D} \underline{g}_{s s}
$$

where I is the identity matrix. Equation (11) is the equation for the cumulative effect of erosion and armouring on the grading of the armour layer. To calculate this equation we need only know the initial grading of the armour $\underline{g}_{0}$, and subsurface layer, $g_{s s}$, the depth of erosion relative to the depth of the armour layer during that time step, $\frac{\Delta E}{D}$, and the armouring marginal transition matrix $\mathbf{A}$. The amount of erosion in the time step $\Delta E$ is defined as $\Delta E=E \Delta t$ where $E$ is the erosion rate per unit time in units of depth/time, and $\Delta t$ is the time step. We will return to how the transition matrix is calculated below.

\subsubsection{Weathering of the Surface}

[21] For weathering we will initially consider the case of physical weathering where the particles in the armour are broken into smaller pieces and this fragmentation is mass conservative. The mass conservative weathering equation is

$$
\underline{g}_{w}=\underline{g}_{r}+\Delta W \underline{B}_{r}=(\mathbf{I}+\Delta W \mathbf{B}) \underline{g}_{r}
$$

where $\Delta W$ is the amount of weathering that occurs per time step, $\mathbf{B}$ is the weathering marginal transition matrix (which is nondimensional), and the weathering per time step $\Delta W$ is defined in terms of a weathering rate, $W$, as $\Delta W=W \Delta t$. The weathering rate, $\mathrm{W}$, has units of $1 /$ time since it is the timescale for weathering rate. Note that the initial grading used in this equation is the result after applying erosion and armouring and is consistent with equations (3) and (6).

[22] The assumption of mass conservation is not essential and we can model nonconservative weathering processes. Chemical dissolution is not mass conservative because particulate matter is dissolved and is leached out of the soil so that the mass of particles decreases over time. It is not modeled in this version of mARM but proposed here for future reference. Dissolution can be calculated as an additional step on equation (12) that has a similar form to equation (10)

$$
\underline{g}_{s}=\left[\mathbf{I}-\frac{\Delta S}{D} \mathbf{C}\right] \underline{g}_{w}+\frac{\Delta S}{D} \underline{g}_{s s}
$$

where $\Delta S$ is the equivalent depth loss for the armour as a result of dissolution of the mineral matter in the armour. Note the dissolution mass balance differs from the previous steps because dissolution normally results in a reduction in bulk density of the armour as pores in the soil particles are created. Thus the equivalent depth loss $\Delta S$ is not necessarily equal to mass loss in the armour layer divided by the bulk density, but is somewhat less. Equation (13) does not account for these bulk density changes.

\subsubsection{Armour Evolution}

[23] Equations (11) and (12) allow us to predict the evolution of the armour grading over time as a result of erosion, armouring and physical weathering. We only need to define the soil initial conditions, the erosion and weathering rates ( $E$ and $W$, respectively) and the grading transition matrixes for calculating erosion and weathering (A and $\mathbf{B}$, respectively).

$$
\underline{g}_{t+1}=[\mathbf{I}+\Delta W \mathbf{B}]\left[\mathbf{I}-\frac{\Delta E}{D} \mathbf{A}\right] \underline{g}_{t}+\frac{\Delta E}{D}[\mathbf{I}+\Delta W \mathbf{B}] \underline{g}_{s s}
$$

where $g_{t+1}$ is the armour grading at the end of the time step after all the processes are applied. To evolve the landform this equation is applied repeatedly with $\underline{g}_{t}$ at each time step being the $\underline{g}_{t+1}$ from the previous time step. Note that we do not need to assume that the transition matrices are constant over time. The transition matrices $\mathbf{A}$ and $\mathbf{B}$ can evolve from time step to time step, but during each time step they are constant.

[24] Moreover, it is possible to define the equilibrium armour grading by noting that at equilibrium the initial and final gradings in equation (14) are equal (i.e., $\underline{g}_{t+1}=\underline{g}_{t}$ ) so that the equilibrium soil grading $\underline{g} *$ is

$$
\underline{g}^{*}=\frac{\Delta E}{D}\left[\mathbf{I}-[\mathbf{I}+\Delta W \mathbf{B}]\left[\mathbf{I}-\frac{\Delta E}{D} \mathbf{A}\right]\right]^{-1}[\mathbf{I}+\Delta W \mathbf{B}] \underline{g}_{s s}
$$

[25] This equation appears at first sight to have a dependency on time step through $\Delta E$ and $\Delta W$. However, if we substitute $\Delta W=W \Delta t$ and $\Delta E=E \Delta t$ in equation (15) and divide through by $\Delta t$ we obtain

$$
\underline{g}^{*}=\frac{E}{D}\left[\frac{E}{D} \mathbf{A}-W \mathbf{B}+\frac{W E}{D} \Delta t \mathbf{B A}\right]^{-1}[\mathbf{I}+W \Delta t \mathbf{B}] \underline{g}_{s s}
$$

and if let $\Delta t \rightarrow 0$ so that the time step is small then the equilibrium soil profile is

$$
\underline{g}^{*}=\left[\mathbf{A}-\frac{W D}{E} \mathbf{B}\right]^{-1} \underline{g}_{s s}
$$

[26] This equation indicates that (1) the time step dependency is an artifact of the numerical approximation inherent in the state-space formulation and (2) the equilibrium grading is a function of the relative importance of the erosion and weathering as given by the nondimensional number $\frac{W D}{E}$ where $\frac{W D}{E}$ small indicates that the soil is erosion/ armouring dominated (i.e., $W D \ll E$ ). If the weathering rate is zero (i.e., $W=0$ ) then this simplifies to

$$
\underline{g}^{*}=\mathbf{A}^{-1} \underline{g}_{s s}
$$

[27] Note that for equations (15)-(18) the transition matrices are those that apply for the equilibrium grading $g^{*}$. If the transition matrices are dependent on the armour grading then it is likely that these equilibrium equations would need to be solved iteratively. The solution steps would be (1) an initial guess of the equilibrium grading is 
made, (2) calculate the marginal transition matrices using the current estimate of the grading, (3) estimate a new grading using equations (15) or (18), and (4) return to step 2. The numerical procedure captures the idea that it is necessary to solve both the transition matrix and the equilibrium grading vector simultaneously.

\subsubsection{Erosion Physics}

[28] The derivation of the state-space matrix evolution approach outline above does not assume any specific constitutive equations for erosion, armouring and weathering. In this section we outline the physics we adopt hereafter in this paper. We adopt the physics below simply to demonstrate the numerical solution of these equations and to allow us to compare the results from mARM with our ARMOUR model, not because the approach in equations (1)-(18) inherently requires the physics outlined below. The erosion rate $(E)$ we use in this paper is

$$
E=e \frac{q^{\alpha_{1}} S^{\alpha_{2}}}{d_{50 a}^{\beta}}
$$

where $e$ is the erodibility factor, $q$ is discharge per unit width $\left(\mathrm{m}^{3} / \mathrm{s} / \mathrm{m}\right), S$ is slope, $d_{50 a}$ is the median diameter of the material in the armour layer and $\alpha_{1}, \alpha_{2}$ and $\beta$ are exponents which need to be calibrated. In the case of planar slope with constant slope then the exponents $\alpha_{1}$ and $\alpha_{2}$ can be directly derived from the shear stress dependent erosion physics [see, e.g., Willgoose et al., 1991]; otherwise, they need to be calibrated. In this paper we consider only a onedimensional, hillslope with constant width and runoff excess generation down the slope, $r$, so discharge is

$$
q=r x
$$

where $q$ is the overland flow discharge per unit width $\left(\mathrm{m}^{3} / \mathrm{s} / \mathrm{m}\right)$, and $x$ is the distance from the most upstream point.

[29] The erosion transition matrix entries are the amount of erosion/unit time in each of the size classes per unit of total erosion. The transition matrix $\mathbf{A}$ is diagonal with the off-diagonal elements being zero. The diagonal elements of A, $A_{k k}$, are

$$
A_{k k}=\left\{\begin{array}{ccc}
\frac{a}{d_{k}^{m}} g_{k} & \text { for } & k<M \\
b \frac{a}{d_{k}^{m}} g_{k} & \text { for } & k=M \\
0 & \text { for } & k>M
\end{array}\right.
$$

where $d_{k}$ is the mean diameter of size class $k(k=1$ is the smallest diameter grading class), the power $m$ needs to be calibrated, $a$ and $b$ are scaling factors, and $M$ is a size threshold that determines the largest particle diameter that can be entrained in the flow (determined by the Shields stress threshold). For $m>0$ in equation (21) the amount of sediment eroded in each size class increases as grain size diameter decreases (reflecting an increase in mobility as grain size decreases) and decreases as the proportion of that size class $g_{k}$ in the armour decreases (reflecting its reduced exposure to entrainment).

[30] The scaling factor $a$ is determined to ensure

$$
\sum_{i} \sum_{j} A_{i j} g_{j}=\sum_{k=1}^{M} A_{k k} g_{k}=1
$$

where the double summation required by mass conservation can be simplified to a single summation by noting that for erosion all off-diagonal terms in $\mathbf{A}$ are zero. Equation (22) ensures that the total amount of sediment eroded in equation (11) is $\Delta E$.

[31] To determine the scaling factor $b$ we need to determine the largest particle diameter, $d_{t h}$, that can be entrained. This is determined by the Shield's shear stress threshold

$$
d_{t h}=\frac{1}{F_{s}} \frac{\tau_{0}}{\gamma(s-1)}
$$

where $\tau_{0}$ is the bed shear stress $\left(\tau_{0}=\gamma R_{h} S\right), R_{h}$ is the hydraulic radius, $F_{s}$ is the Shields entrainment threshold, $\gamma$ is the unit weight of water, and $s$ is the specific gravity of the sediment (here we assume $s=2.65$ ). Using the Manning equation to calculate $R_{h}$

$$
R_{h}=(n q)^{0.6} S^{-0.3}
$$

where $n$ is Manning friction factor, leads to the equation for threshold diameter in terms of discharge and slope

$$
d_{t h}=21.6(n q)^{0.6} S^{0.7}
$$

[32] The value of $M$ in equation (21) is then determined such that for class $M d_{t h}$ falls inside the $M$ th class's size range. For the class range $M$ the $A_{M M}$ is decreased by the proportion of the class range below $d_{t h}$ so that

$$
b=\frac{d_{t h}-d_{l}}{d_{u}-d_{l}}
$$

where $d_{u}$ and $d_{l}$ are the upper and lower bound diameters for size class $M$, respectively.

\subsubsection{Weathering Physics}

[33] The weathering transition matrix (B) defines the relative change in each grading class $(i)$ as a result of the fracturing of particles in the weathering mechanism. A single grading class will lose a proportion of its volume to one or more smaller classes. This proportion is a function of the distribution of the classes, the mechanics of the fracturing and the characteristics of the daughter particles [see, e.g., Wells et al., 2008]. This process is shown in Figure 1 for an example where particle breaks into two daughter particles of different volumes. If multiple daughter particles (with a corresponding range of volumes) are created by weathering then the mathematics is more complicated but the principle is the same.

[34] The particle breakdown rule for the generation of two daughter particles is that a parent particle of diameter $d$ breaks into two particles of diameters $d_{1}$ and $d_{2}$. If dissolution does not occur (i.e., below we model only physical weathering) so that mass conservation is true $\left(\sum_{i} \sum_{j} B_{i j} g_{j}=0\right)$ then $d^{3}=d_{1}^{3}+d_{2}^{3}$. If the geometry of breakdown is grain size invariant and $d_{1}=\alpha d_{2}$ then

$$
d_{1}=\frac{d}{\left(1+\alpha^{3}\right)^{1 / 3}}
$$




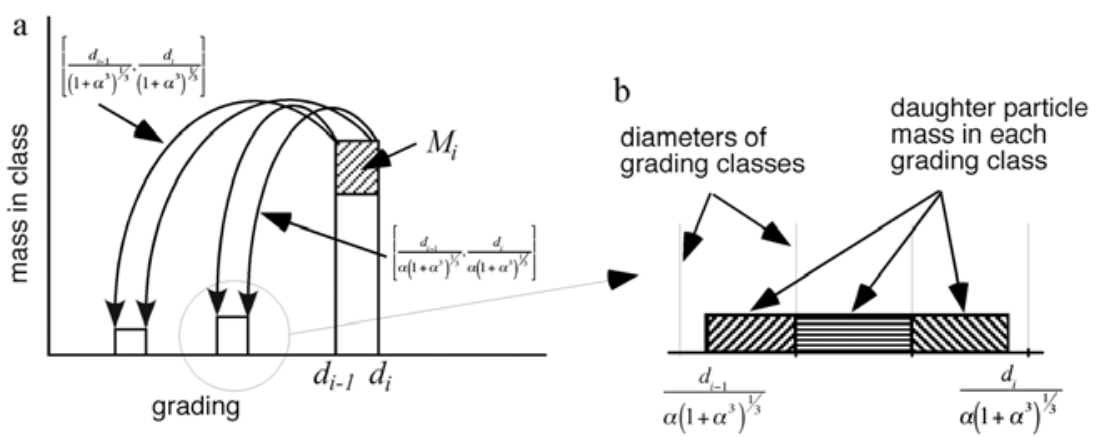

Figure 1. Schematic of the calculation of the weathering transition matrix. (a) The transition between the parent and daughters gradings. (b) The interpolation between size classes normally required across classes for the daughter particles.

[35] Thus the diameters of both daughter fragments can be determined from the diameter of the parent particle, the geometry of fracture and mass continuity. We use equation (27) to determine the range of diameters of daughter particles that are generated from parent particles in a single grading range (Figure 1a). The grading range of particles in class $i$ is $\left[d_{i-1}, d_{i}\right]$ so that by using equation (27) we determine the range of diameters for the smaller of daughter particles as $\left[\frac{d_{i-1}}{\left(1+\alpha^{3}\right)^{1 / 3}}, \frac{d_{i}}{\left(1+\alpha^{3}\right)^{1 / 3}}\right]$ and for the larger particles as $\left[\frac{d_{i-1}}{\alpha\left(1+\alpha^{3}\right)^{1 / 3}}, \frac{d_{i}}{\alpha\left(1+\alpha^{3}\right)^{1 / 3}}\right]$. This is obtained by calculating equation (27) for the upper and lower bounds of the grading ranges. If the mass of material being weathering from grading range $i$ is $\mathrm{M}$ (the hatched area in Figure 1a) then the mass of particles in the smaller range is $\frac{M}{1+\alpha^{3}}$ and in the larger range is $\frac{M \alpha^{3}}{1+\alpha^{3}}$. The process of determining what the cumulative daughter products are from weathering of all of the parent grading ranges involves calculating the numbers above for all parent grading ranges and summing up the grading ranges for all the daughter particles.

[36] There are a number of complicating factors in the calculation. The first is that the grading range of the daughter particles will not necessarily fall on the grading ranges of the discretization of the soil grading used in the calculations (Figure 1b). Legros and Pedro [1985], SalvadorBlanes et al. [2007], and Wells et al. [2008] used one thousand $1 \mu \mathrm{m}$ "boxes" to represent soil distribution in their profile weathering models enabling high-resolution transition between grading classes. Their approach is computationally inefficient and generates numerical artifacts, and is therefore not suitable here. In ARMOUR to avoid this problem weathering was calculated from an average particle size for each class and daughter particles contribute to only two smaller grading classes, corresponding to the size of the two daughter particles. This can result in simulations from ARMOUR having spiky grading artifacts over time.

[37] Instead mARM uses interpolation to allocate the mass of daughter products to the requisite size ranges in the discretization of the grading (Figure 1). This avoids the spiky artifacts from ARMOUR.

[38] Finally in the calibration of the "two daughter particle" model above Wells et al. [2008] found it more convenient to express everything in terms of the mass fractions generated in each of the size ranges. This allowed their simulations to be consistent with the method of measurement of weathering breakdown experiments of sediment mixtures in their experiments. Wells et al. [2008] showed that is possible to calibrate the diameter-based conceptualization outlined above to mass-based data, and they used this calibration to uniquely identify the daughter product geometry factor $\alpha$.

\subsection{Some Example Transition Matrices}

[39] Some examples of transition matrices are outlined below to clarify the preceding presentation. For clarity these are presented for a very simple soil grading, $g$, with just two soil fractions where $g_{1}$ is the fine fraction and $g_{2}$ is the coarse fraction, with diameters $d_{1}$ and $d_{2}$, respectively.

3.3.1. Erosion and Armouring

[40] Example 1 is as follows: If all the erosion occurs from the fine fraction and none from the coarse fraction, then

$$
\mathbf{A}=\left[\begin{array}{cc}
k & 0 \\
0 & 0
\end{array}\right]
$$

where conservation of mass requires from equation (22) that $\sum A_{i i} g_{i}=1$ so that $k=\frac{1}{g_{1}}$, where $i$ is the index of the rows and columns in $\mathbf{A}$.

[41] Example 2 is as follows: The proportion of the two size fractions 1 and 2 is in the proportion $\alpha$ so that class 1 is $\alpha$ times more mobile than class 2 so that

$$
\mathbf{A}=\left[\begin{array}{cc}
k_{1} & 0 \\
0 & k_{2}
\end{array}\right]
$$

where $\sum_{i} A_{i i} g_{i}=A_{11} g_{1}+A_{22} g_{2}=1$ and $k_{1}=\alpha k_{2}$, yielding

$$
k_{2}=\frac{1}{\left(\alpha g_{1}+g_{2}\right)}
$$

\subsubsection{Weathering}

[42] The main difference between erosion and weathering is that, in the absence of dissolution, mass balance is maintained through the weathering cycle so that $\sum_{j} A_{i j} g_{j}=$
0 for all $i$, so that $\sum \sum A_{i j} g_{j}=0$. 0 for all $i$, so that $\sum_{i} \sum_{j} A_{i j} g_{j}=0$.

[43] Example 3 is as follows: As for the erosion example above we will consider the simplest possible scenario, with 
two size classes, 1 and 2 . Consider the case where $10 \%$ of the mass of grading class 2 breaks into particles of class 1 in one time step, and where no breakdown occurs of particles in class 1. The marginal transition matrix $\mathbf{B}$ is

$$
\mathbf{B}=\left[\begin{array}{ll}
0 & k_{1} \\
0 & k_{2}
\end{array}\right]
$$

where $\sum_{i} \sum_{j} A_{i j} g_{j}=k_{1} g_{2}+k_{2} g_{2}=0$ so that by continuity $k_{2}=-k_{1}$. If $10 \%$ of the material in class 2 is removed during each time step then $k_{1}=-k_{2}=-0.1$.

[44] Example 4 is as follows: This example extends example 3 to look at materials with more than 2 size classes, in this case 3 classes, a diameter-dependent weathering rate and what happens over multiple time steps. If $10 \%$ of class 3 breaks into class $2,5 \%$ of class 2 breaks into class 1 and no breakdown occurs in class 1 , then the marginal transition matrix is

$$
\mathbf{B}=\left[\begin{array}{ccc}
0 & 0.05 & 0 \\
0 & -0.05 & 0.1 \\
0 & 0 & -0.1
\end{array}\right]
$$

where the numbers in the matrix are derived in the same way they were for equation (31), but where there is now a size-dependent weathering rate. Note the lower triangular portion of the matrix is zero because particles can only get smaller not larger. These zero entries are a general characteristic of marginal transition matrices for physical weathering. For chemical weathering, however, the cementation of particles together by precipitates or gangue minerals can potentially generate larger diameter daughter particles in which case the lower triangle would no longer be zero. Note also that the zero entry in the top right corner is because, in this example in one time step, particles from grading class 3 do not break down into class 1 .

[45] Let us now consider what happens over multiple time steps. The equation for the grading change over two time steps is

$$
\underline{g}_{t+2 \Delta t}=(\mathbf{I}+\mathbf{B}) \underline{g}_{t+\Delta t}=(\mathbf{I}+\mathbf{B})(\mathbf{I}+\mathbf{B}) \underline{g}_{t}=(\mathbf{I}+\mathbf{D}) \underline{\mathbf{g}}_{\mathbf{t}}
$$

where the subscripts on $g$ here refer to the time step not the grading class, and where $\mathbf{D}$ is the marginal transition matrix for two time steps. This two time step matrix is

$$
\mathbf{D}=2 \mathbf{B}+\mathbf{B}^{2}=\left[\begin{array}{ccc}
0 & 0.0975 & 0.005 \\
0 & -0.0975 & 0.185 \\
0 & 0 & -0.19
\end{array}\right]
$$

[46] Note that the structure is very similar to the one time step matrix $\mathbf{B}$ except that its entries are approximately twice the magnitude of the single step matrix. This can formalized. When $\mathbf{B}$ is small (so that $\|\mathbf{B}\| \gg\left\|\mathbf{B}^{2}\right\|$ where $\|\ldots\|$ is the norm of the matrix) then $\mathbf{D} \approx 2 \mathbf{B}$. As the time step becomes smaller the matrix entries $\mathbf{B}$ become smaller and the approximation $\mathbf{D}=2 \mathbf{B}$ improves. The other thing to note about equation (34) is that all of the entries in the upper triangular part of the matrix are nonzero. In particular, in contrast to $\mathbf{B}$ the top right corner entry of $\mathbf{D}$ is nonzero. This is because in the first time step some class 3 particles go to class 2 , while at the second time step some particles in class 2 move to class 1 , so if we model the two time steps, in one time step that is twice as long, particles in class 3 can contribute to class 1 , albeit quite small quantities.

\section{Data Used in This Study}

[47] The soil grading, topographic and meteorological characteristics of the Ranger Uranium Mine (Northern Territory, Australia) spoil site were used in this study. The site we use was described in detail by Willgoose and Sharmeen [2006]. The grading distribution for this site is coarse-stony metamorphics and the experiment used a $24 \mathrm{~m}$ hillslope with a constant gradient of $2.1 \%$. Willgoose and Sharmeen divided it into six equally spaced nodes, and we do likewise for consistency. Measured runoff data in Ranger [Willgoose and Riley, 1998] was used in the ARMOUR study to calculate discharge and was interpolated into an approximately 100-year data set [Sharmeen and Willgoose, 2007]. We used a 200-year simulation, with an output of nearly 50000 time steps, as a baseline for our calibration and evaluation procedure.

\section{Model Calibration}

[48] The physics of mARM (as presented above) and ARMOUR are comparable. This gives us confidence in the model simplification compromises. However, the new conceptualization used in mARM leads to a mathematically different model. In addition, simplifications have been made in the way discharge is calculated. While ARMOUR uses detailed time-varying runoff data (described by Sharmeen and Willgoose [2007]), mARM uses time-averaged values. The models physical parameters are therefore not entirely comparable and need to be calibrated if we are to mach their predictions.

\subsection{Armouring Component}

[49] We calibrated mARM to the ARMOUR model to demonstrate that the physical model conceptualization inherited in mARM can match the dynamics of hillslope armouring simulated by ARMOUR and validated by Willgoose and Sharmeen [2006]. With the physically based model ARMOUR we can exercise the model to ensure that we test all aspects of hillslope sediment temporal dynamics. Willgoose and Sharmeen [2006] showed that it can be difficult to fully exercise all aspects of armouring with field data. For instance, ARMOUR provides detailed quantitative prediction of armour grading on a hillslope for periods of up to hundreds and thousands of years, something that is difficult to achieve in field or laboratory experiments. It is for that reason that we calibrate $\mathrm{mARM}$ to another model (ARMOUR) rather then directly from field data, despite the compromise inherent in this approach.

[50] Calibration of mARM adjusts (1) the relationship between discharge $(q)$ and slope and erosion rate (equation (19)) and (2) the influence of mean diameter $\left(d_{k}\right)$ on erodibility (equation (21)). Controlling these relationships is done by the appropriate exponents $\left(e, \alpha_{1}, \alpha_{2}, \beta\right.$ and $m$ ) and the Manning friction factor $(n)$ in equation (25). Initial ARMOUR $\alpha_{1}, \alpha_{2}, \beta$ and $m$ values were used for the 

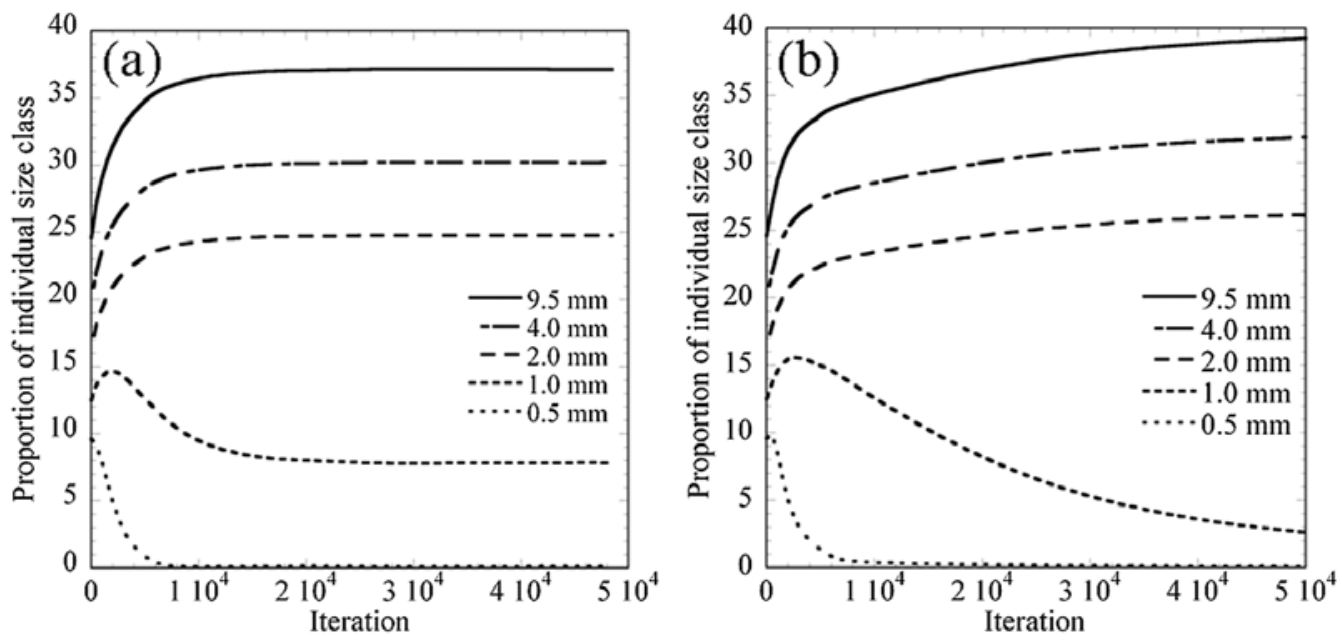

Figure 2. Proportion of the coarsest five (out of 18) size classes (in $\mathrm{mm}$ ) in the overall soil grading over time (50,000 iteration is equivalent to 200 years) in (a) ARMOUR and (b) mARM. These results are from the outlet node of a $24 \mathrm{~m}$ hillslope equally divided into six 4 m nodes.

calibration procedure [Willgoose and Sharmeen, 2006]. They were then fine tuned to match the armouring simulation of ARMOUR for the Ranger experiments (24 m long, $2.1 \%$ hillslope divided into six equal nodes, 200-year simulations) by finding the best fit of trends with time.

[51] We calibrated the armouring component of mARM by fitting the time-varying particle size distribution plots to the time varying particle size distributions of the ARMOUR simulations at each of the six nodes down the hillslope. Figure 2 shows the change at the five coarsest size classes at the hillslope outlet node for both models. We were able to achieve a good match between mARM and ARMOUR in the calibration, with a maximum variation of $5 \%$ in the grading distribution over the 200 -year simulation.

[52] The differences between ARMOUR and mARM results occur due to a difference in the behavior of just one grading class, the most erodible grading class in each node. As demonstrated in Figure 2 the $1.0 \mathrm{~mm}$ class reached an equilibrium in the ARMOUR simulation (Figure 2a) while this class does not reach an equilibrium in mARM (Figure $2 b$ ). This is due to the simplified way the Shields transport threshold is treated within mARM. In ARMOUR discharge is calculated from observed time varying rainfall data while $\mathrm{mARM}$ uses a time averaged constant. The range of discharges in ARMOUR results in a close to equilibrium erosion-deposition relationship. This does not occur in mARM due to its constant discharge which leads to continuing erosion.

[53] This change affects the coarser classes as well since their proportions increase as a result. Since this difference in behavior only results in a maximum difference of $5 \%$ at the end of the 200-year simulation, and the fact the weathering component was not activated in these simulations, we are confident in the capability of mARM to satisfactorily simulate the armouring process.

[54] The final values of the calibrated parameters are $\alpha_{1}=1, \alpha_{2}=1.2, \beta=1, m=4, e=0.025$ and $n=0.1$. The value of $\beta=1$ suggests an inverse relationship between erosion and $d_{50}$ which differs from typical empirical observations and previous parameter fits (around 0.75 [Henderson,
1966; Willgoose and Sharmeen, 2006]). Our analysis reveals the results of mARM were insensitive to $\beta$ variations ranging from 0.5 to 1.5 . The effect of changes in $\beta$ was mainly on the rates, not on the trends of the results.

\subsection{Weathering Component}

[55] The weathering component of mARM was calibrated to the Wells et al. [2008] experimental data. Wells et al. [2008] measured and simulated the change in the mass of five grading classes as a result of physical weathering of a rock from the Ranger site. They found a good fit between laboratory experimental data of salt weathering of rock and a fracture model where a parent particle generated two daughter particles of equal volume. By using the same equal volume daughter products in mARM we matched their laboratory and simulation results (Figure 3 ).

\section{Parametric Study}

[56] In the previous section we used the Ranger data [Willgoose and Sharmeen, 2006] to calibrate the armouring component of the mARM model. In this section we compare $\mathrm{mARM}$ and ARMOUR results for a range of conditions in order to examine the robustness of our new model. We simulated the armouring (with no weathering) of a 24 m hillslope with 6 equally spaced nodes for (1) two contrasting slope gradients ( 1 and 20\%), (2) 50\% reduced runoff, and (3) a finer initial soil grading. ARMOUR and mARM were compared by examining the simulated $d_{50}$ of the surface armour (i.e., the median diameter) of the hillslopes.

[57] The 50000 iteration simulations (equivalent to 200 years) correspond well to both final $d_{50}$ values and behavior in most cases (Figure 4). The largest difference in $d_{50}$ was for the low slope gradient simulations in which mARM has predicted a $4.4 \mathrm{~mm} d_{50}$ at node 2 (Figure 4a) while ARMOUR predicted a $d_{50}$ of $4.9 \mathrm{~mm}$ (Figure $4 \mathrm{~b}$ ). This node also exhibited the most significant differences in behavior over time. The reduced runoff simulation showed nearly identical results to the low-gradient simulations 

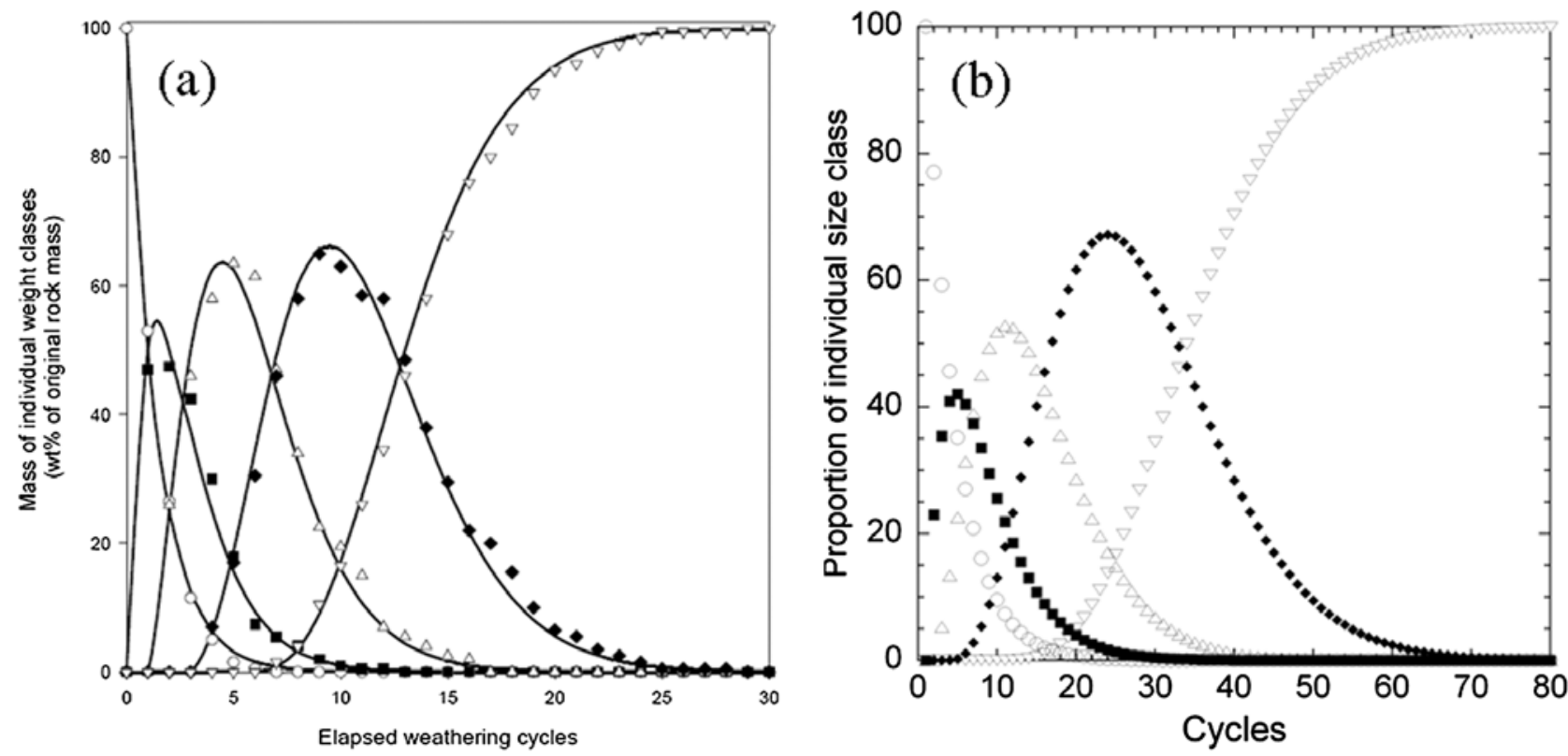

Figure 3. Change in weight class proportion over cycles of weathering. (a) Wells et al. [2008] analytical (line) and Monte Carlo simulations and (b) mARM weathering component simulation: circles, $>50 \%$; squares, $25-50 \%$; triangles, $10-25 \%$; diamonds, $1-10 \%$; inverted triangles, $<1 \%$. The particle grading here is divided into five weight classes for better comparison with the Wells et al. [2008] results.

(Figures $4 \mathrm{a}$ and $4 \mathrm{~b}$ ). We do not discuss these further other than to note that this indicates an equivalence in behavior between low discharge and low slope, something we will return to later.

[58] The differences observed in the calibrations (Figure 2) where the largest erodible class did not reach an equilibrium in mARM can also be seen in both the low and high slope gradient results (Figures $4 \mathrm{a}$ and $4 \mathrm{c}$ ). Unlike the asymptotic equilibrium behavior shown by ARMOUR the $d_{50}$ values of most mARM nodes continue to increase. As noted before this is a result of mARM approximating entrainment in the size class within which the Shield's threshold falls and its effect on the other grading classes is small other than this limitation. We believe that mARM's ability to approximate the more physically based ARMOUR is robust.

[59] In the finer initial soil comparison we used the grading of the Northparkes Gold Mine (New South Wales, Australia) spoil site [Willgoose and Sharmeen, 2006]. The soil grading of this site was chosen since Willgoose and Sharmeen [2006] found its cohesive characteristics resulted is significant differences compared to the noncohesive Ranger Mine grading. Figures $4 \mathrm{e}$ and $4 \mathrm{f}$ show close similarities between mARM and ARMOUR final $d_{50}$ predictions and behavior in all six nodes.

\section{Combined Armouring-Physical Weathering Simulations}

\subsection{Effect of Weathering Rate on Soil Distribution}

[60] In this section we used the calibrated mARM from the previous sections to explore the response of a onedimensional hillslope to the interaction between the armouring and physical weathering processes. Figure 5 shows the results of four simulations (6 nodes, $24 \mathrm{~m}$ slope at $2.1 \%$ slope) with different physical weathering rates. The extreme low weathering rate (Figure 5a) produced results that were nearly identical to the no-weathering simulation on the same hillslope. With an increased weathering rate (by a factor of 10 , Figure $5 \mathrm{~b}$ ) the soil grading starts to decrease after an initial steep increase. This steep increase is the result of erosion of the initial soil grading which is relatively abundant with fine erodible materials. Once the erodible materials have been removed (after approximately 10000 iterations) the surface was armoured. The decrease in $d_{50}$ after this time is solely the result of the weathering process breaking down the armour layer particles. This later decrease in $d_{50}$ indicates that a transition occurred where the weathering rate dominated the erosion and armouring rate resulting in a transport-limited erosion regime.

[61] After increasing the weathering rate by an additional factor of 10 (Figure 5c) we see a more substantial dominance of the weathering process over armouring in the evolution of surface grading. Nodes 1 and 2 (which are higher on the hillslope and therefore have less runoff and erosion) are completely dominated by weathering. At these nodes there is no increase in $d_{50}$ at the beginning of the simulation, indicating that no armour has been created. Nodes which are lower on the hillslope (3-6) still show some armouring in the early stages of the simulation. The nodes reach a state of equilibrium after 15,000 to 20,000 iterations with relatively large differences in the $d_{50}$ between the two uphill nodes (1 and 2) and the rest of the nodes.

[62] For the highest weathering rate (Figure 5d; a further factor of 10 increase) the entire hillslope is completely weathering dominated. No armour was created anywhere and the differences in equilibrium surface grading between the nodes are small. This latter observation is important because armouring creates a grading distribution that varies downslope (with discharge) while weathering, if spatially uniform, creates a distribution that is the same everywhere. 

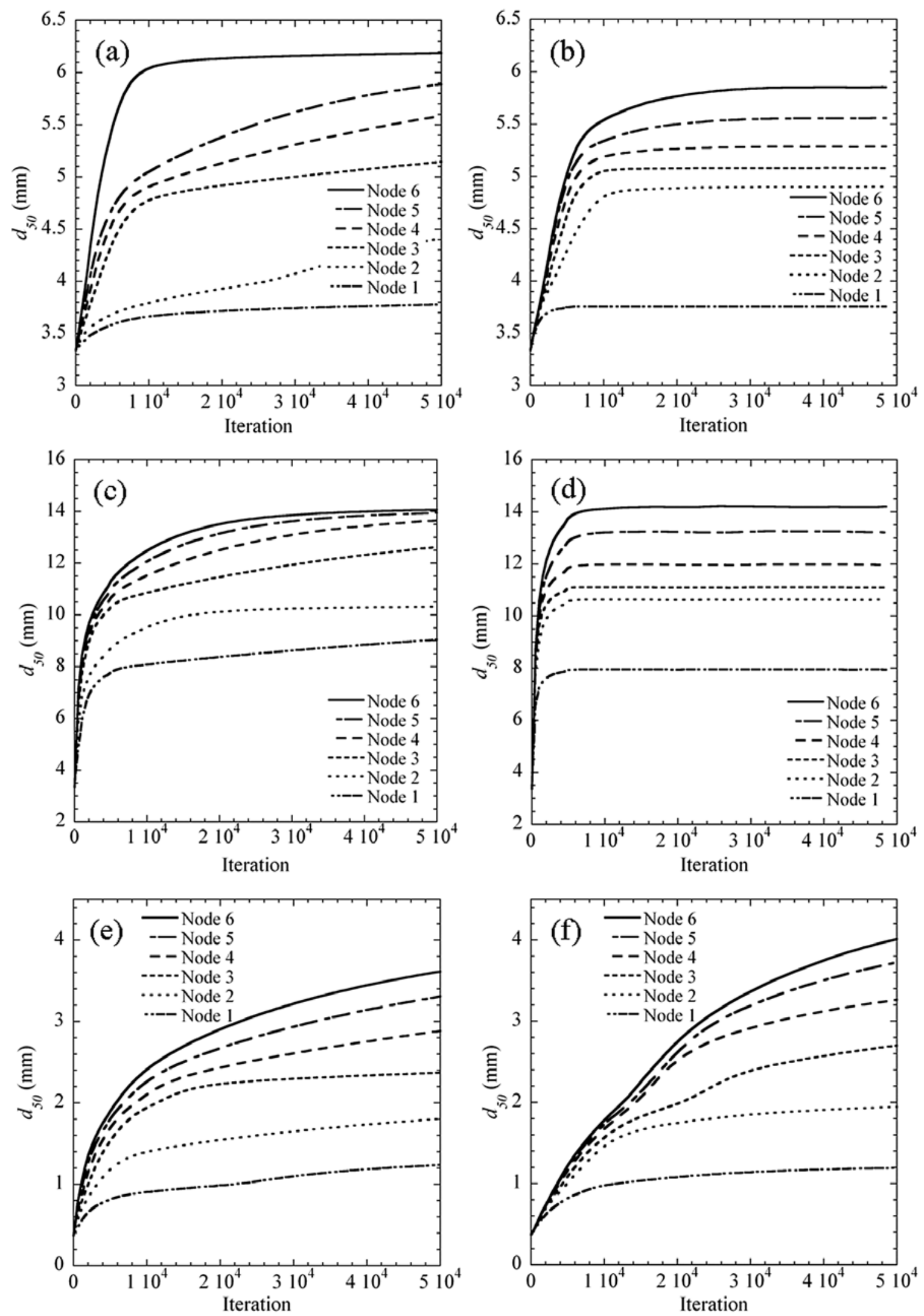

Figure 4. Median diameter $d_{50}$ of the surface in six equally spaced nodes (node 1 is the most upstream node) on a $24 \mathrm{~m}$ hillslope in (a) mARM using 1\% slope; (b) ARMOUR using 1\% slope; (c) mARM using $20 \%$ slope; (d) ARMOUR using 20\% slope; (e) mARM with finer initial soil grading using $2.1 \%$ slope; (f) ARMOUR with finer initial soil grading using $2.1 \%$ slope. 

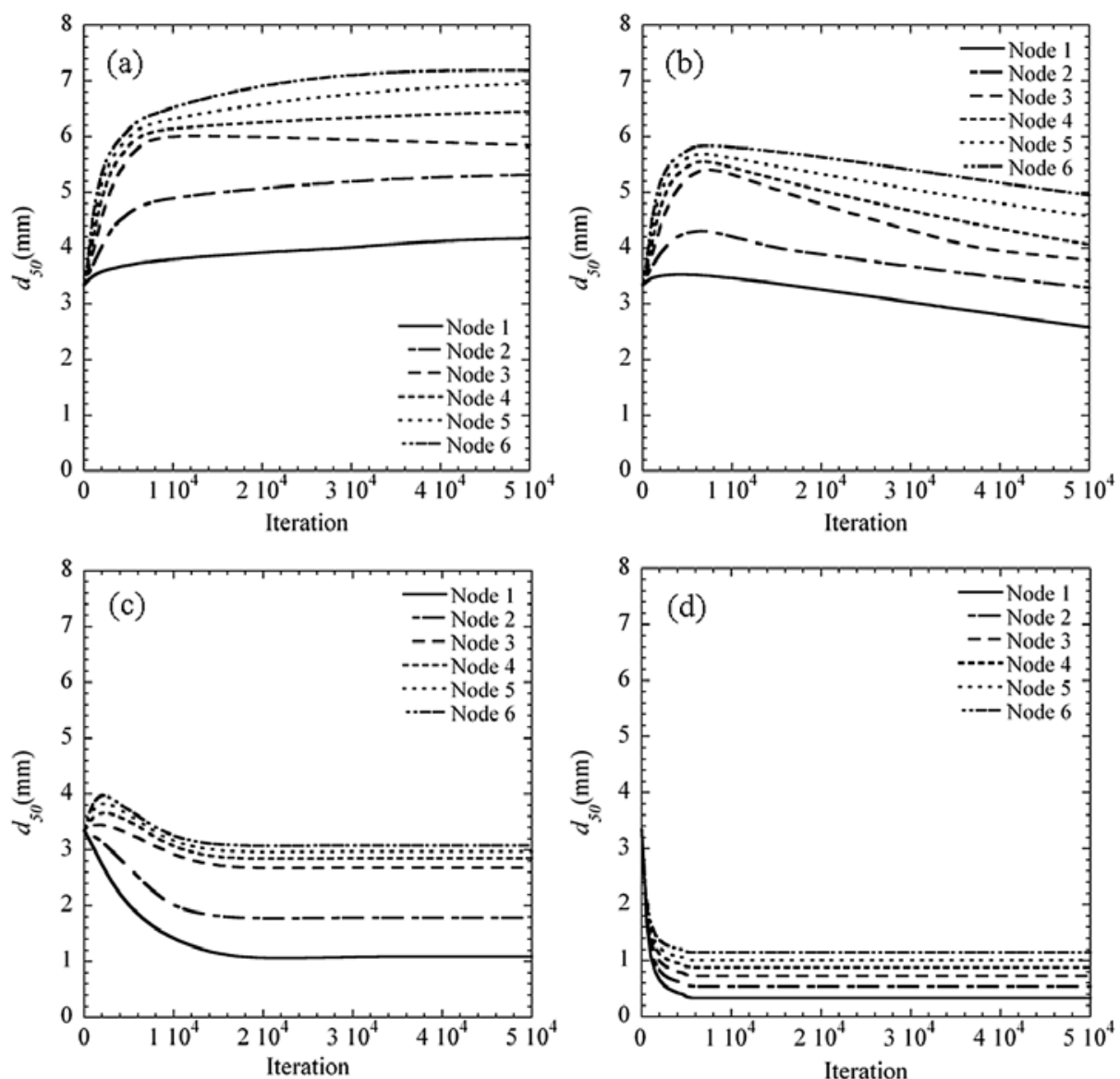

Figure 5. Median diameter $d_{50}$ of the surface in six equally spaced nodes (node 1 is the most upstream node) on a $24 \mathrm{~m}$ hillslope in under different weathering rates: (a) factor of 0.1 ; (b) factor of 1 ; (c) factor of 10 ; (d) factor of 100 .

But here we see that even for extreme high weathering rates (where erosion rates are relatively negligible) there are still differences between the equilibrium grading of the nodes downstream which demonstrates the significance of the armouring-weathering coupling process postulated by Sharmeen and Willgoose [2006].

[63] Our results agree well with the findings of Sharmeen and Willgoose [2006] on the interaction between armouring and physical weathering and its effect on soil distribution and erosion regimes.

\subsection{Area-Slope- $d_{50}$ Relationship}

[64] The significant reduction in run time by the mARM model (about $10^{4}$ times faster than ARMOUR) allows us to conduct a wide array of simulations under different conditions that are not feasible with ARMOUR. In this section we explore relationships between geomorphologic parameters and soil distribution derived from one-dimensional hillslope simulations. Figure 6 shows the $\log -\log$ distribution of equilibrium $d_{50}$ along four hillslopes with different slopes $(2.1,5,10$ and $20 \%)$. We found strong correlations $\left(\mathrm{R}^{2}>0.9\right.$; $\mathrm{p}<0.005)$ for all four hillslopes. This suggests the existence of a spatial link between contributing area and slope and soil characteristics. This relationship is further examined below.

[65] The relationship between contributing area, slope and $d_{50}$ was plotted for different weathering rates. We used

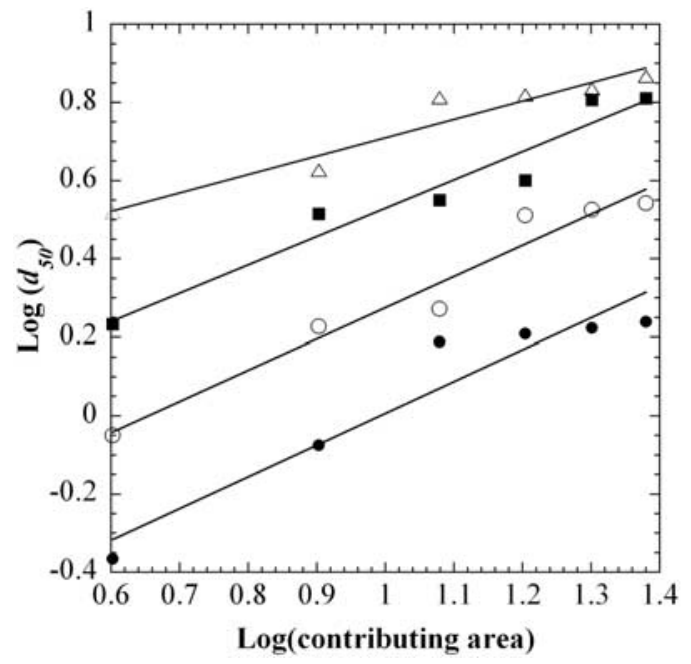

Figure 6. Soil slope grading (in logarithmic values) as a function of contributing area (also in logarithmic values) derived from four hillslope simulations (with grading of the following: solid circles, 2.1; open circles, 5.0; solid squares, 10.0 ; open triangles, $20.0 \%$ ) divided to six equally spaced nodes. 

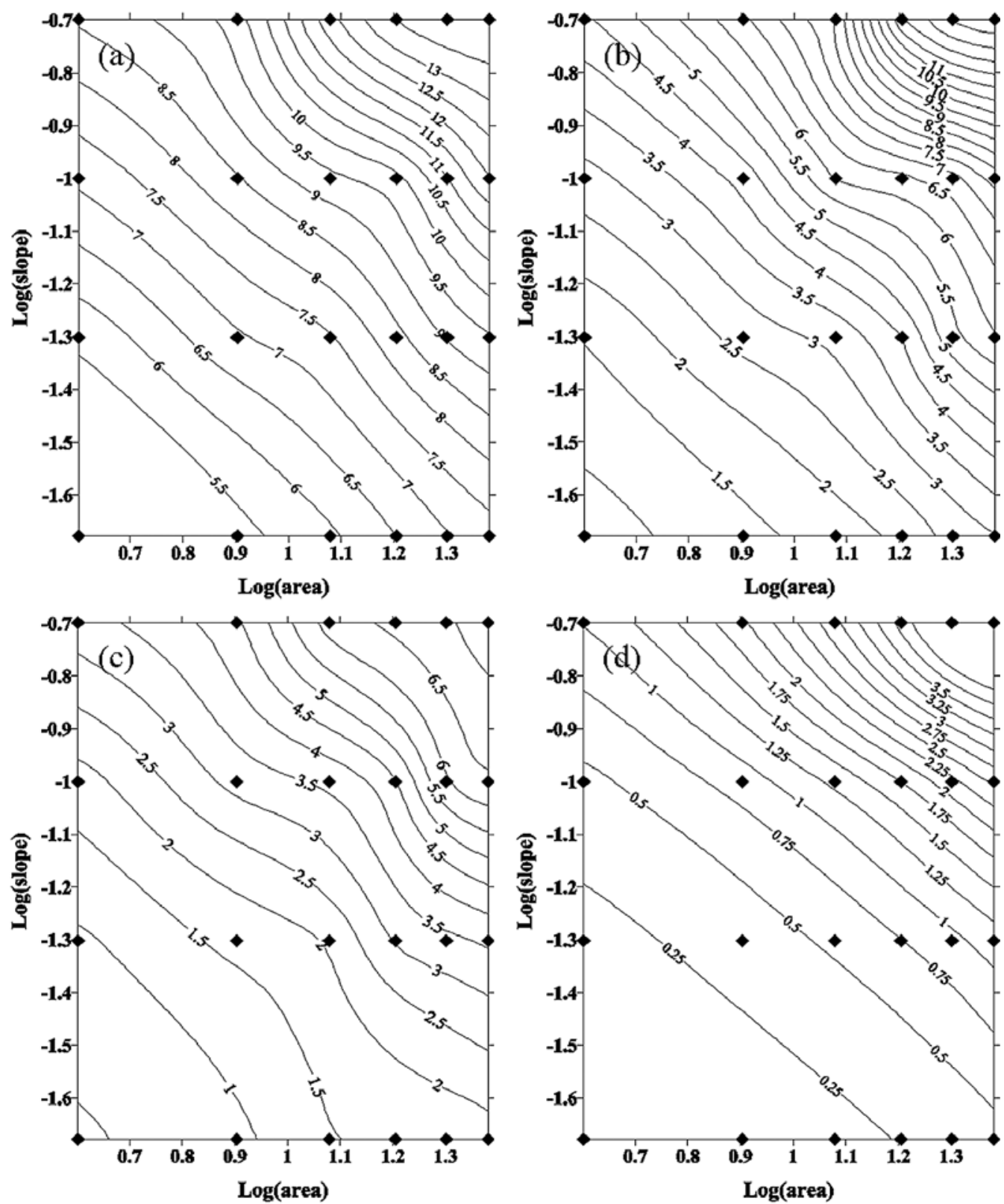

Figure 7. Contour maps of $d_{50}$ values interpolated from 24 nodes (diamonds) simulated by mARM (contributing areas of 4, 8, 12, 16, 20, and $24 \mathrm{~m}$ in logarithmic values and slops of 2.1, 5, 10, and 20\% in logarithmic values). Each map was simulated with a different weathering rate: (a) 0.01, (b) 0.1, (c) 1.0 ,

contour maps and multiregression analysis to visualize and quantify these relationships. Figure 7 show four of those contour maps (created by the Kriging interpolation algorithm in the Surfare 8.0 package) in which the logarithms of contributing area and slope are plotted on the $x$ and $y$ axes (respectively) and equilibrium $d_{50}$ is interpolated between 24 measuring points. In each map these measuring points were derived from four hillslopes with different slopes (2.1, 5, 10 and 20\%) divided to six equal nodes (with contributing areas of 4, 8, 12, 16, 20 and $24 \mathrm{~m}$ ).

[66] All four contour maps show a strong relationship in which $d_{50}$ values increase as a function of area and slope. The $d_{50}$ decreases as weathering rate increases which is consistent with our results for the hillslope comparison (Figure 6).
The three lower weathering rate maps (Figures $7 \mathrm{a}-7 \mathrm{c}$ ) are quite similar in their contour arrangement while the extreme high weathering map has stronger log-log linear contours and shows a tendency for higher density contours for higher area and slope. The consistency of these log-log linear contours with a range of physical weathering rates suggests that weathering rates have a relatively small influence on the slope of the area-slope- $d_{50}$ relationship.

[67] Table 1 summarizes the three parameters of the area-slope- $d_{50}$ multiregression analysis

$$
d_{50}=c A^{\alpha} S^{\beta}
$$

where $A$ is contributing area (with exponent $\alpha$ ) and $S$ is slope (with exponent $\beta$ ). The $c$ intersect decreases as the 
Table 1. Summary of the Parameters of the $d_{50}$-Area-Slope Multiregression Analysis for Different Weathering Rates ${ }^{\mathrm{a}}$

\begin{tabular}{ccccc}
\hline Weathering Rate & $c$ & $\alpha$ & $\beta$ & $\alpha / \beta$ \\
\hline 0.01 & 9.21 & 0.29 & 0.3 & 0.97 \\
0.1 & 5.0 & 0.68 & 0.7 & 0.97 \\
1.0 & 3.19 & 0.7 & 0.7 & 1.0 \\
10.0 & 1.66 & 0.98 & 1.18 & 0.82 \\
\hline
\end{tabular}

${ }^{\mathrm{a}}$ Here $d_{50}=c A^{\alpha} S^{\beta}$. The $d_{50}$ values are from 200-year equivalent simulations on a six nodes planar $24 \mathrm{~m}$ hillslope which was simulated with four different slopes.

weathering rate increases. Soil becomes finer as physical weathering becomes more dominant. The area and slope exponents ( $\alpha$ and $\beta$ ) have a positive correlation with weathering rate. They both show similar trends, an increase in value between the lowest and the second lowest weathering rates followed by nearly identical values between weathering rates of 0.1 and 1.0 and finally an increase in value in the extreme high weathering rate. The change in $\frac{\alpha}{\beta}$ (the slope of the log-log contours) is small (a maximum of 0.18 ) for all cases. These results suggest that the area-slope- $d_{50}$ relationship is robust. This has important implications in soil distribution calculation since it shows that we can theoretically extract soil grading as a function of area and slope.

\section{Discussion}

[68] All the one-dimensional hillslopes we used in this study had a constant slope which led to a common behavior in all the simulations, downslope coarsening. Even under extreme weathering and erosion rates all the downslope nodes had coarser soil grading than the nodes upslope. Unlike our one-dimensional hillslope natural catenary hillslopes will have distinct units which vary in their topographic slope and pedogeomorphic properties [Conacher and Dalrymple, 1977]. Accordingly, soil properties along a natural catena will usually show a more complex change [e.g., Brunner et al., 2004] than the general downhill coarsening simulated by both ARMOUR and mARM. A general description of soil distribution along a catena is coarsening from the summit to the shoulder and backslope (where slopes and erosions are high) followed by fining in the footslope [Birkeland, 1974]. This overall downslope fining is usually caused by deposition of fine material in the footslope where slopes are low. There are many variations to the above description [e.g., Bonifacio et al., 1997] as a result of varying soil depths, weathering rates, erosion distribution, pedogenesis, etc. [Birkeland, 1974].

[69] One limitation of the approach outlined here is that that it implicitly assumes that soil does not move downslope either by (1) erosion and subsequent deposition or (2) soil creep. This limitation means that adjacent nodes on the hillslope do not directly interact. The only interaction between adjacent nodes is via the overland flow that drives erosion. This limits applications to hillslopes without deposition. To overcome this limitation would, we believe, require incorporating $\mathrm{mARM}$ into a landform evolution model where erosion and deposition spatially couple points on the hillslope and drive the evolution of the landform. This will also be true for modeling creep.
[70] A more complex description of natural hillslopes (e.g., flow divergence and convergence and deposition) is beyond the scope of the one-dimensional models presented in this paper. One of our planned applications of mARM is as a pedogenesis component in a landform evolution model, where deposition is calculated for transport-limited erosion. The main advantage of models such as mARM, even in its simplest form, is the ability to disaggregate the components of hillslope processes which allow us to look at specific parameters and processes which cannot be done in the field. Moreover, the matrix formulation allows us to determine long-term equilibrium soil grading directly from the mechanics of armouring and weathering. This will allow us to potentially develop analytic expressions for soil catena in terms of the physical component of soil evolution. Future work is aimed at extending the mARM framework outlined in the first half of the paper to examine the evolution of the full profile of the soil, not just the surface armour layer, for each point on a grid distributed in space. This will provide the framework for us to simulate, in a computationally efficient way, the interaction between soil profile pedogenesis and soil hillslope catena. This work will be reported in due course.

\section{Conclusions}

[71] Hillslope scale simulation of armouring and weathering is an important step in the investigation of these processes and their influence on soil and morphology. Our goal is to explore these important processes on a larger scale. This was impractical with existing models (e.g., ARMOUR). We developed a simplified conceptual model, mARM, which dramatically decreases the numeric complexity and thus computer run time (on a $2.4 \mathrm{Ghz}, 2 \mathrm{G}$ RAM CPU a simulation of a 6 node hillslope over 200 years takes approximately $65 \mathrm{~min}$ in ARMOUR and about $0.4 \mathrm{~s}$ in mARM, a speedup of nearly $10^{4}$ ) enabling multiple largescale simulations. mARM utilizes the physical characteristics of ARMOUR in a framework which computes the complex spatial interactions.

[72] Armouring-weathering simulations by mARM (Figure 5) illustrate the influence of increasing weathering rate on soil grading and armour development on a hillslope. We found that even for large weathering rates, while an armour layer may develop quickly it will slowly be reduced to a weathering dominated (transport-limited) erosion regime. For extreme weathering rates (relative to erosion rates) no armour layer is formed on the surface and the soil grading quickly reaches a state of equilibrium and very fine soil grading. These results agree well with the findings of Sharmeen and Willgoose [2006].

[73] The area-slope- $d_{50}$ relationship and contour maps demonstrated that a log-log linear relationship between area, slope and $d_{50}$ is found and is robust against changes in erosion and weathering rates. This has important implications for soil distribution mapping because it potentially allows a major simplification in soil modeling as it allows us to link soil grading distribution to geomorphology (i.e., upslope drainage area and slope), which can be used in GIS applications.

[74] One important advantage of the matrix formulation developed here is that, in addition to the temporal evolution 
of soil, the method also allows us to predict the equilibrium soil that the system evolves to over millennia. This will be the focus of future investigations, as it will allow us to quantitatively link pedogenesis processes and climate with observed soil properties.

[75] Our new model allows a more detailed exploration of hillslope response to the weathering and armouring processes. The work presented here showed that mARM is able to simulate surface grading in response to the armouring and weathering processes in a much simpler manner albeit with some physical simplification. mARM can now be used for large spatial scale simulations which will provide important insights on the spatial distributions of the armouring and weathering processes and their affect on soil development and organization.

[76] Finally we note that the mathematical framework for mARM that we have presented in this paper is completely general, and not restricted by the process dynamics of any individual mechanism involved in soil evolution. We have demonstrated the approach here with two soil processes, armouring due to erosion and physical weathering. We picked these two processes because this allowed us to compare the framework with a detailed physically based and computationally intensive model (ARMOUR) we have previously studied. However, our framework is equally applicable to other soil processes. By way of illustration, in the derivation of this framework we showed how chemical weathering could be simulated with this framework. We believe the generality of the mARM framework, the transparency of the model formulation and its computational efficiency can underpin quantitative studies of pedogenesis and provide a quantitative framework for understanding soil hillslope catena.

[77] Acknowledgments. We acknowledge the exceptionally thorough reviews of this paper by two reviewers and the Associate Editor. We also acknowledge the financial support of Australian Research Council grants DP0667093 and DP0556941. S.C. is partially supported by a University of Newcastle Faculty of Science Ph.D. scholarship, and G.R.W. is supported by an Australian Professorial Fellowship.

\section{References}

Andrews, E. D., and G. Parker (1987), Formation of a coarse surface layer as the response to gravel mobility, in Sediment Transport in Gravel Bed Rivers, edited by C. R. Thorne, J. C. Bathurst, and R. D. Hey, pp. 269300, Wiley, Chichester, U. K.

Ashida, K., and M. Michiue (1971), An investigation of river bed degradation downstream of a dam, in Proceedings of the 14th Congress, pp. 247-255, Int. Assoc. of Hydraul. Eng. and Res., Paris.

Birkeland, P. W. (1974), Soils and Geomorphology, 372 pp., Oxford Univ. Press, New York.

Bonifacio, E., E. Zaninia, V. Boeroa, and M. Franchini-Angelab (1997), Pedogenesis in a soil catena on serpentinite in north-western Italy, Geoderma, 75(1-2), 33-51.

Brunner, A. C., S. J. Park, G. R. Ruecker, R. Dikau, and P. L. G. Vlek (2004), Catenary soil development influencing erosion susceptibility along a hillslope in Uganda, Catena, 58(1), 1-22.

Celia, M. A., and W. G. Gray (1991), Numerical Methods For Differential Equations: Fundamental Concepts For Scientific and Engineering Applications, Prentice-Hall, Upper Saddle River, N. J.

Conacher, A. J., and J. B. Dalrymple (1977), The nine unit landsurface model-An approach to pedogeomorphic research, Geoderma, 18(1-2), $1-154$.
Gessler, J. (1970), Self-stabilizing tendencies of alluvial channels, J. Waterw. Harbors Coastal Eng. Div., 96, 235-249.

Green, E. G., W. E. Dietrich, and J. F. Banfield (2006), Quantification of chemical weathering rates across an actively eroding hillslope, Earth Planet. Sci. Lett., 242, 155-169.

Henderson, F. M. (1966), Open Channel Flow, Macmillan, New York.

Hoey, T. B., and R. Ferguson (1994), Numerical-simulation of downstream fining by selective transport in gravel-bed rivers-Model development and illustration, Water Resour. Res., 30, 2251-2260.

Klimpel, R. R., and L. G. Austin (1965), Statistical theory of primary breakage distributions for brittle materials, Trans. Am. Inst. Mech. Eng., 232, 88-94.

Legros, J. P., and G. Pedro (1985), The causes of particle-size distribution in soil profiles derived from crystalline rock, France, Geoderma, 30, $15-25$.

Lerman, A. (1979), Geochemical Processes: Water and Sediment Environments, Wiley, New York.

Little, W. C., and P. G. Mayer (1976), Stability of channel beds by armouring, J. Hydraul. Div. Am. Soc. Civ. Eng., 102, 1647-1661.

Nouh, M. (1990), The self armoring process under unsteady-flow conditions, Earth Surf. Process. Landf., 15, 357-364.

Parker, G., and P. C. Klingeman (1982), On why gravel beds streams are paved, Water Resour. Res., 18, 1409-1423.

Parker, G., and A. J. Sutherland (1990), Fluvial armor, J. Hydraul. Res., 28, $529-544$.

Proffitt, G. T. (1980), Selective transport and armouring of non-uniform alluvial sediments, research report, Dep. of Civ. Eng., Univ. of Canterbury, Christchurch, New Zealand.

Riebe, C. S., J. W. Kirchner, and R. C. Finkel (2004), Erosional and climatic effects on long-term chemical weathering rates in granitic landscapes spanning diverse climate regimes, Earth Planet. Sci. Lett., 224, 547-562.

Robertson, D., M. D. Bolton, and G. R. McDowell (1997), A numerical representation of fracturing granular materials, Int. J. Numer. Anal. Methods, 21, 825-843.

Ross, S. M. (1993), Introduction to Probability Models, 5th ed., Academic, Boston.

Salvador-Blanes, S., B. Minasny, and A. B. McBratney (2007), Modelling long-term in situ soil profile evolution: Application to the genesis of soil profiles containing stone layers, Eur. J. Soil Sci., 58, 1535-1548.

Sharmeen, S., and G. R. Willgoose (2006), The interaction between armouring and particle weathering for eroding landscapes, Earth Surf. Process. Landf., 31, 1195-1210.

Sharmeen, S., and G. R. Willgoose (2007), A one-dimensional model for simulating armouring and erosion on hillslopes: II. Long term erosion and armouring predictions for two contrasting mine spoils, Earth Surf. Process. Landf., 32, 1437-1453.

Wells, T., P. Binning, G. Willgoose, and G. Hancock (2006), Laboratory simulation of the salt weathering of schist: I. Weathering of schist blocks in a seasonally wet tropical environment, Earth Surf. Process. Landf., 31, $339-354$.

Wells, T., G. Willgoose, and G. Hancock (2008), Modeling weathering pathways and processes of the fragmentation of salt weathered quartzchlorite schist, J. Geophys. Res., 113, F01014, doi:10.1029/2006JF000714.

Willgoose, G. R., and S. Riley (1998), The long-term stability of engineered landforms of the Ranger Uranium Mine, Northern Territory, Australia: Application of a catchment evolution model, Earth Surf. Process. Landf., 23, 237-259.

Willgoose, G. R., and S. Sharmeen (2006), A one-dimensional model for simulating armouring and erosion on hillslopes: I. Model development and event-scale dynamics, Earth Surf. Process. Landf., 31, 970-991.

Willgoose, G., R. L. Bras, and I. Rodriguez-Iturbe (1991), A physical explanation of an observed link area-slope relationship, Water Resour. Res., 27(7), 1697-1702.

Yokoyama, T., and Y. Matsukura (2006), Field and laboratory experiments on weathering rates of granodiorite: Separation of chemical and physical processes, Geology, 34, 809-812.

S. Cohen and G. Willgoose, School of Engineering, University of Newcastle, Callaghan, NSW 2308, Australia. (garry.willgoose@newcastle. edu.au)

G. Hancock, School of Environmental and Life Sciences, University of Newcastle, Callaghan, NSW 2308, Australia. 